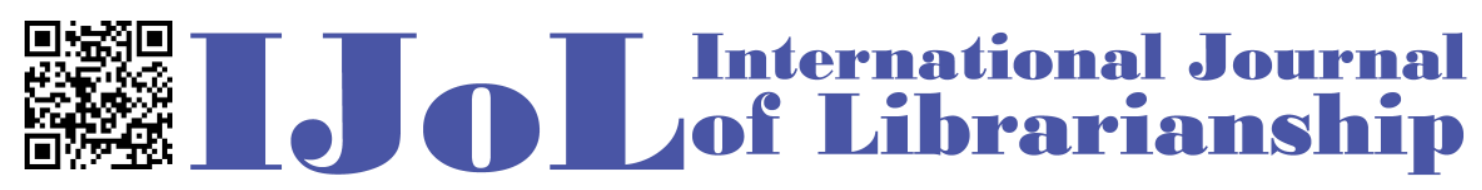

ISSN: 2474-3542 Journal homepage: http://journal.calaijol.org

\title{
Embedding Library Services in Research Stages: Chinese Subject Service and the Research Lifecycle Model
}

Shu Liu

\begin{abstract}
:
Through in-depth interviews, we analyzed user needs at different stages of scientific research, and constructed a library service model that can be practically integrated into all research stages. This article highlights the subject service model in use in Chinese academic libraries and demonstrates how it can work to support researchers across the research lifecycle.
\end{abstract}

To cite this article:

Liu, S. (2017). Embedding library services in research stages: Chinese subject service and the research lifecycle model. International Journal of Librarianship, 2(1), 16-31. https://doi.org/10.23974/ijol.2017.vol2.1.24

To submit your article to this journal:

Go to http://ojs.calaijol.org/index.php/ijol/about/submissions 


\title{
Embedding Library Services in Research Stages: Chinese Subject Service and the Research Lifecycle Model $^{1}$
}

\author{
Shu Liu \\ Peking University Library, Beijing, China
}

\begin{abstract}
Through in-depth interviews, we analyzed user needs at different stages of scientific research, and constructed a library service model that can be practically integrated into all research stages. This article highlights the subject service model in use in Chinese academic libraries and demonstrates how it can work to support researchers across the research life-cycle.
\end{abstract}

Keywords: library services, Chinese university libraries, research stages, research model

\section{INTRODUCTION}

Academic research has experienced dramatic changes, becoming more process-flow oriented, data intensive and collaborative, and libraries in China and elsewhere are transforming their services to better meet the needs of researchers. Subject service, also called academic service or discipline service (hereafter referred to as subject service), is a new service model being adopted by university libraries in China. This model takes into account the different disciplines of the researchers and provides active, positive in-depth, personalized and convenient services for the researchers. In areas with a longer established tradition of the subject service or "liaison" model, research university libraries offer intensive research support services not only as an important part of library services but also as a strategic development plan for the whole library (Cornell University Library, 2011), and researchers have investigated the utility of these services through a research life-cycle model (Vaughan et al, 2013). But this type of investigation has not been carried out before in China. Peking University library now provides a variety of research support services, including high-level research consulting, data analysis, academic exchange, intellectual property and publishing services (Peking University Library, n. d. b). How well does Peking University's subject service model work to support researchers across the entire research lifecycle? In order to investigate this question, the author used a series of in-depth interviews to analyze library service needs at different stages of scientific research. By applying the life-cycle service model to research activities in school of mathematical sciences at Peking University, the

\footnotetext{
${ }^{1}$ Material from this paper will be presented at IFLA WLIC 2017 (August 2017) in Wrocław, Poland.
} 
author demonstrated the usefulness and significance of the research lifecycle model to Chinese subject service.

\section{LITERATURE REVIEW}

Emily McKenzie (2014) discussed strategies that have been successful when approaching research groups, as well as identifying initiatives that may be amenable to adaptation for the same purpose. Vaughan et al (2013) used the research life-cycle model to analyze services at a large university in the U.S., and Ina Fourie and Suzanne Bakker (2012) reported on a service model for a manageable research cycle which was pioneered at the Central Cancer Library of the Netherlands Cancer Institute. Moving on to research that has been conducted in Chinese libraries, Pang Bei (2012) found that the librarian's role has already been transformed to the extent that it is much more integral to the work of the researchers, and required to provide support at each stage of research cycles. Xue Wang (2014) analyzed the subject information demand of readers at different stages of scientific research, and tried to construct a subject service model for scientific research by taking the example of services for Northeast Institute of Geography and Agroecology Chinese Academy of Science. Song, Guo and Wei (2012) focused on how to provide high quality services for the researchers in Shanghai Jiaotong University. The work of these scholars shows the role of the library in the research process, in part. But few studies have looked at library services targeted across the whole cycle of research at universities in China.

According to Jisc (2013), the U.K. higher education consortium, the research lifecycle is generally considered to contain four main elements: idea discovery, proposal writing, research process and publication, which roughly correspond to the research stages we discuss in this paper: project preparatory stage, research and development stage, results or output stage(Figure 1).

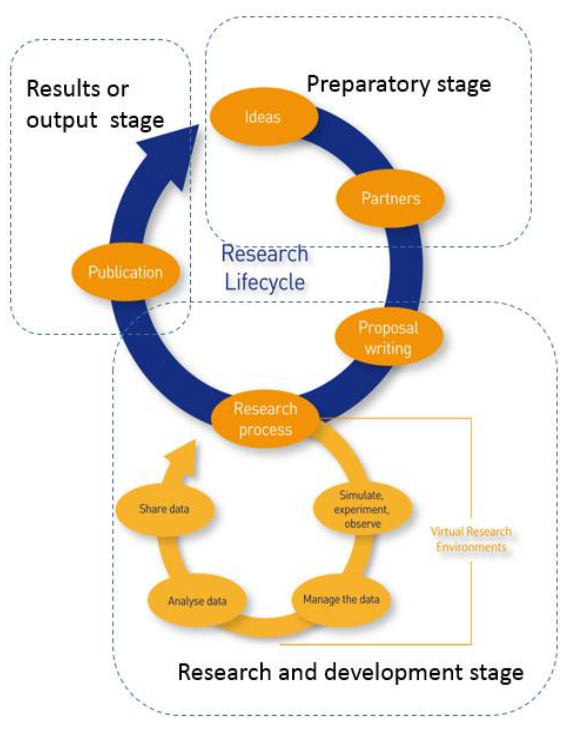

Figure 1. Model for research stages based on JISC Research Lifecycle. Reprinted from https://www.webarchive.org.uk/wayback/archive/20140615113149/http://www.jisc.ac.uk/whatw edo/campaigns/res3/jischelp.aspx\#simulate 


\section{METHOD}

This study was intended to be exploratory and to suggest different and richer library services, given new requirements and issues that researchers are facing. Therefore, a qualitative, ethnographic approach to information collection and analysis was important.

The author conducted face-to-face interviews with a total of 30 researchers in the school of mathematical sciences at Peking University. Interviews were conducted on site at the branch library of mathematics; the author approached researchers who were using the library and asked if they would be willing to be interviewed. She continued this process over multiple visits until she had interviewed the total of 30. Interviewees possessed a high level of education, all of them with science training. 10 percent (3/30) had bachelor's degrees, 20 percent (6/30) had master's degrees, 70 percent (21/30) had doctoral degrees(Figure2), all of which were in science fields, and all had studied or worked in the school for between one and ten years. Considering our interviewees' busy schedules, interviews were limited to 30min. Interviews were spread over a two-week period at the end of September and early October 2016 when the author visited the institute. All interviews were conducted in Chinese.

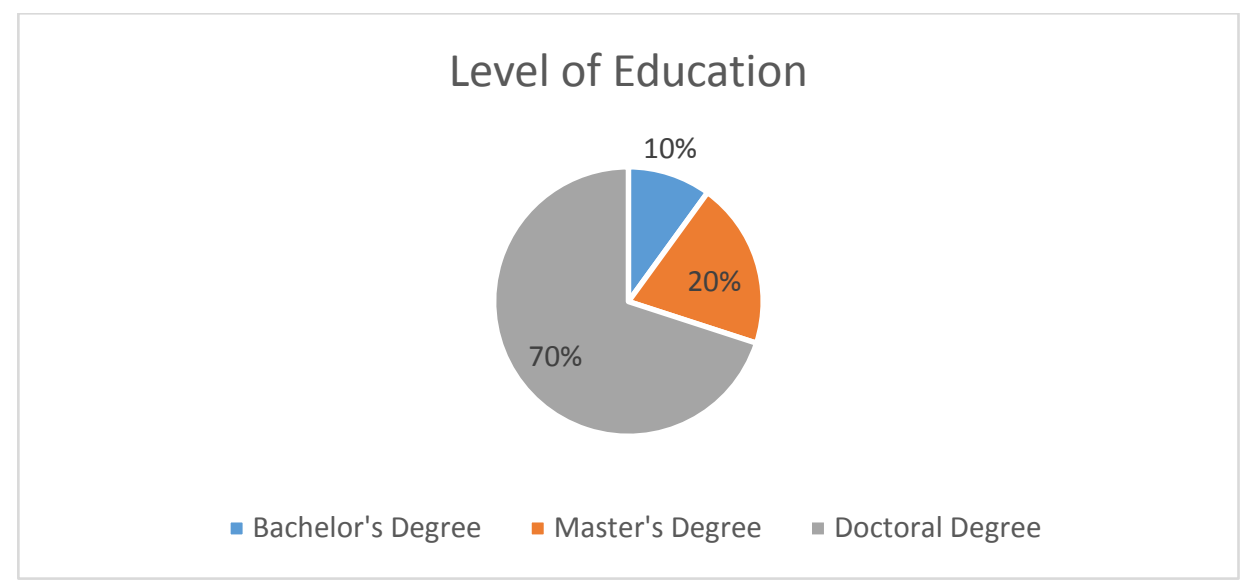

Figure 2. Education of interviewees

\section{SURVEY RESULTS}

The structured interviews consisted of 8 questions that were asked of all participants. Interviewees were also shown a list of 15 library services. The author selected the services by discussing librarians' experience, reading services descriptions from various library web sites, and reading articles in the LIS database. (All listed services are offered by Peking University Library). The questions were designed to test the value of the library service model and gain insights on how to effectively deploy the model. The questions most relevant to the current research project are: 
1. What do you need libraries to do during project preparatory stage of scientific research? (Shows list.) Please select the services you are interested in. Could you also suggest other services you need?

2. What do you need libraries to do during the Development and Research Phase of scientific research? (Shows list.) Please select the services you are interested in. Could you also suggest other services you need?

3. What do you need libraries to do during the Results and output stage of scientific research? (Shows list.) Please select the services you are interested in. Could you also suggest other services you need?

The full text of all interview questions and the complete list of services can be found in the appendix to the article.

Figure 3 shows the services that interviewees most commonly selected as ones they were interested in. As it shows, nearly all interviewees would like libraries to provide research information, research data management, and data analysis consulting services.

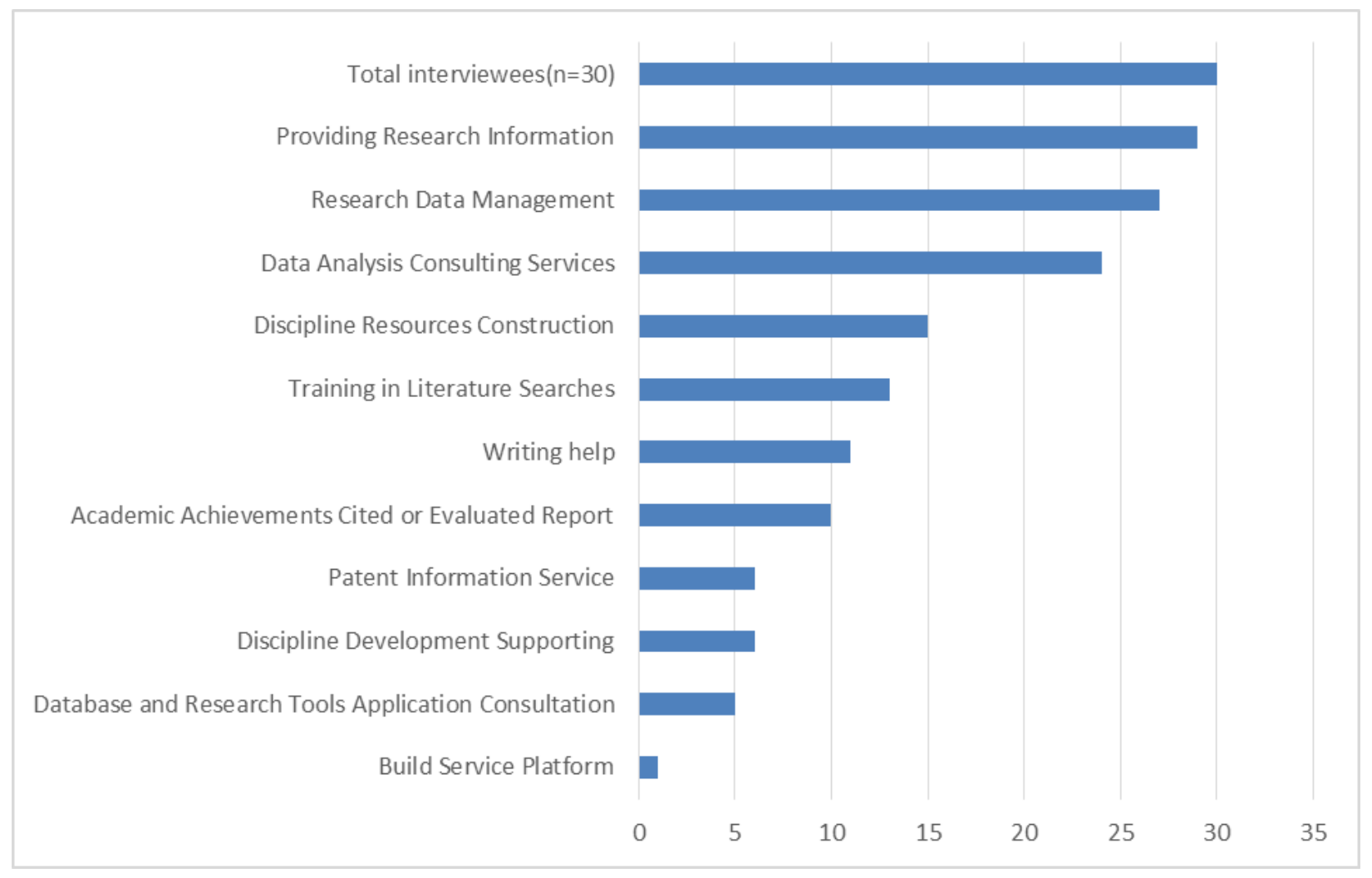

Figure 3. Most Commonly Selected Services

These services can be assigned to the stages of the Jisc research lifecycle model as follows:

- Project preparatory stage: 97 percent (29/30) of respondents selected Providing Research Information; about 50 percent (15/30) selected Discipline Resources Construction; 20 percent (6/30) noted Discipline Development Supporting (all of these had doctoral degrees); about 43 percent (13/30) selected Training in Literature Searches; just 3 percent (1/30) selected Building Service Platforms. 
- Research and development stage: 90 percent (27/30) of responses selected Research Data Management, and about 60 percent (24/30) selected Data Analysis Consulting (12 of the 24 specifically mentioned Financial Mathematics). 16 percent (5/30) selected Database and Research Tools Application Consultation.

- Results and output stage: 20 percent (6/30) of responses selected Patent Information Service, and about 33 percent (10/30) noted Academic Achievements Cited or Evaluated Reports; 20 percent (11/30) noted Writing help.

During the research process, users have different needs at different stages, and at each stage, there are opportunities for libraries to provide researchers with different services. Using both personnel and technological solutions, libraries should construct a subject service model that works across the research stages, covering service content, service time and other service aspects. Our researchers were interested in receiving library support at every stage of research.

Obviously it helps librarians to ascertain the depth and breadth of the services they should provide if they are fully familiar with the activities their researchers are engaged in. Based on the interviews, the comprehensive research life cycle model can describe the research librarian's role in three main research stages: project preparatory stage, research and development stage, results and output stage. (See Figure 4)

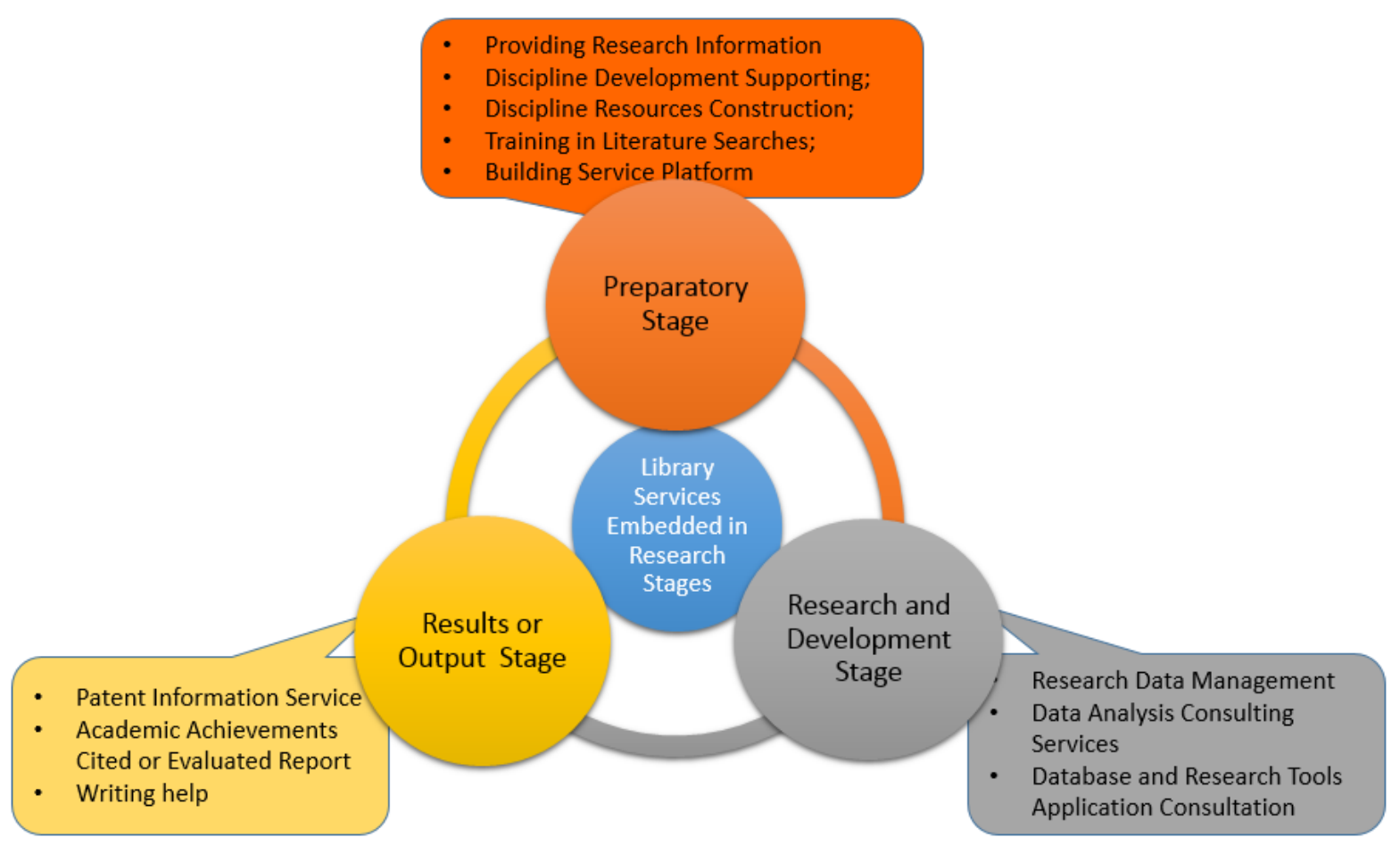

Figure 4. Model for Library Services Based on Scientific Research Stages 
For example, in the project preparatory stage, researchers need to start actively collecting resources. With so many journals in the databases, how do they know which journal to start with? Do they target high impact journals, or are publications in any peer-reviewed journal in their fields adequate? Librarians should learn how to choose and utilize databases and tools available to identify journal titles, their impact and rankings, and play a role in guiding researchers to make a decision on selecting the appropriate journals to meet their specific needs.

\section{FINDINGS AND ANALYSIS}

The following findings and discussions focus on themes relating to professional practice within the subject service / research lifecycle model. The type of support required by a researcher will change based on the discipline within which they are working. More and more, librarians focus on how researchers' needs vary depending on both their discipline and their research stage. For example, at Peking University we have noticed that researchers in the science field tend to prefer Twitter and digital repositories, but researchers in social science fields are less likely to use emerging technologies. The library needs to consider these factors in the development of library resources, library services, library facilities and even the future development of the library, so the library can fully position itself in the research process. Basing on the survey, support services can be provided in every stage of the research process as set forth below.

\section{Project Preparatory Stage}

In recent years at Peking University, more and more librarians are starting to play roles like teacher, subject leader, or even research staff collaborating with researchers. New roles generate a lot of opportunities to increase the visibility of the librarians in a school, especially where libraries are underutilized or librarians are not visible. Collaboration comes from good relationships between the librarian and the researchers.

In the early stages of the research, research activities generally involve designing studies, collecting information and finding the funds to apply for and other activities. The interviewees were asked a question about need for services provided by the libraries at this stage.

\section{Q1: What do libraries need to do during the project preparatory stage of scientific research?}

Services provided by the library at this stage include professional consultations (research consultations), maintaining frequently asked questions (FAQs), creating research guides such as guides to dynamic interdisciplinary research and trend analysis, providing research information (paper documents, online databases and other sources), document retrieval, looking for potential research partners, and providing information sharing spaces. Five major themes emerged for this question. 


\section{Providing research information}

Almost all interviewees (29/30) noted the importance of libraries providing subject collections. They specifically mentioned foreign language books, foreign language periodicals, Chinese books, important conference papers, and electronic resources. The subject service librarian is not only the information collector, but also provides and transmits information to the researcher. All of these resources and services provided by the library allow researchers to follow top information and developments in domestic and international disciplines, stimulate research staff inspire teaching and research, help them identify research projects, clarify research direction, improve work efficiency, and even promote the process of the construction of disciplines.

\section{Discipline development service}

Discipline Development Service is a new service in recent years in Chinese university libraries, which provides support for the research group, the administration, or the discipline ${ }^{2}$, rather than to individual researchers. In Peking University Library, service components include tracking the progress and development at home and abroad of research groups and their rivals, providing dynamic updates on new technologies, and providing patent information related to disciplines (Peking University Library, n. d. a).

Several interviewees (6/30) were familiar with this service. An interviewee who had been involved with department evaluation told us: "During the $4^{\text {th }}$ Chinese discipline evaluation, there were demands for scientific assessments, discipline development, and talent assessment, so we cooperated with the library to ask librarians to get information from the Essential Science Indicators (ESI) and InCites databases. They helped us not only mine top papers, analyze hot papers, and compare and monitor the disciplines between the universities, but also to track talents (editor's note: especially promising or productive researchers / faculty), and mine the special contributions of talents."

During the evaluation of a discipline in Chinese universities, there are demands for scientific assessments, discipline development, talent introduction and talent assessment and decision support. So libraries are asked to use sources such as ESI and InCites databases to not only mine top papers, analyze hot papers, provide personnel tracking and compare and monitor the discipline, but also to study the discipline's frontiers, mine the special contributions of talents, and track, locate, compare and predict discipline competitiveness. For example, in May 2016, the field of physics of Peking University entered the top 1\% in its discipline in ESI for the first time, so the library analyzed the main contributors from 188 highly cited papers published by Peking University from 2006 to 2015 (Table 1, Weiming Academic Express, 2016).

\footnotetext{
${ }^{2}$ Editor's note: roughly equivalent to a subject area or program
} 
Table 1.

Main contributors to the physics discipline at Peking University.

\begin{tabular}{|c|c|c|}
\hline Faculty Name & WOS Published Papers & Contribution rate \\
\hline School of Physics & 148 & 78.72 \\
\hline $\begin{array}{c}\text { School of Chemistry and Mole } \\
\text { Engineering }\end{array}$ & 36 & 19.15 \\
\hline \multicolumn{3}{|c|}{ School of Information Science and } \\
\hline Technology & 27 & 14.36 \\
\hline Institute of Technology & 24 & 12.77 \\
\hline \multicolumn{3}{|c|}{ Advanced Interdisciplinary Research } \\
\hline Institute & 2 & 1.06 \\
\hline School of Mathematics & 1 & 0.53 \\
\hline
\end{tabular}

Note. Reprinted from Peking University increases 1 top $1 \%$ and 1 top $0.1 \%$ disciplines in May 2016, by Weiming Academic Express, July 5, 2016. Retrieved from http://weibo.com/u/5963822635?profile ftype=1\&is_all=1\#_rnd1499825188373. (There are two highly cited papers where we could not verify the departmental attribution.)

\section{Discipline resources construction}

Discipline resources (editor's note: what North American libraries might call "subject collections") are important resources to support teachers and researchers in carrying out teaching and research, and are the foundations on which libraries can deepen their services.

15/30 interviewees selected the construction of discipline resources as important. As one researcher noted, "librarians are the leading constructors for resources, so they should listen to the relevant teachers or researchers in order to make resource development more accurate, suitable and comprehensive." And the author also shares the following email from a researcher in the school of psychology in Peking University: "Annual review of clinical psychology is a very authoritative psychology journal which this department teacher's teaching and research largely depend on, so thanks to the library for purchasing it quickly and thanks for your work." (Translated from Chinese). The value to researchers of resources construction is especially well captured in this story.

Libraries also actively build special resources. During the survey, 10/30 interviewees wanted to know more about the academic achievement ecosystems built by Peking University Library (PKU). This was not one of the listed services but came up in conversations. These include four platforms (PKU Open Research Data; PKU Journal Platform; PKU Institutional Repository; Scholar@Peking University) which support research data management, publishing, storage and communication. Specifically, PKU Institutional Repository (http://ir.pku.edu.cn/) is a central, open-access academic repository of research by members of the Peking University. PKU Open Research Data platform (http://opendata.pku.edu.cn/) is used for publishing, tracking, discovering and reusing the scholars' and institutions' data. PKU Journal Platform includes foreign and Chinese academic journals and internal journals published by various institutions of Peking 
University (http://www.oaj.pku.edu.cn/OAJ/CN/OAJ/home.shtml). And Scholar@Peking University (http://scholar.pku.edu.cn/) provides a convenient network platform for academic scholars to set up personal academic homepages independently.

\section{Training in literature searches}

Although most interviewees (mostly experts and well-established in their field) felt confident about their search skills ("We get acquainted with the field"), there were still 13/30 researchers who remarked that "there is always a need" for training. These researchers want to "be trained, the better the sooner". Specific areas in which the need for further training was noted included: how to use the document management tools, how to consult special databases, and how to access professional books, laws and regulations related to their research.

\section{Building service platforms}

Some libraries construct disciplinary service platforms which integrate appropriate disciplinary resources and services and allow subject librarians and researchers to interact and communicate, such as for example LibGuides at Harvard University (http://guides.library.harvard.edu/) and LibGuides at Cambridge University (http://libguides.cam.ac.uk/). Just one interviewee showed interest in these platforms: "It would be interesting if it could focus on the needs of readers and show the variety of resources of the library, it could be helpful for navigation of library services, and even offer customization services for us." Peking University Library is using the VIP ${ }^{\circledR}$ discipline service platform (http://www.lib.pku.edu.cn/portal/fw/xkfw/xuekeboke).

\section{Development and Research Phase}

At this stage, the needs of users in the school of mathematical sciences are mainly divided into two parts, one is the accumulation and storage of experimental data and another is the need for statistical analysis methods, software and resources. The interviewees were asked about need for services provided by the libraries at this stage.

Q2: What do libraries need to do during the Development and Research Phase of scientific research?

According to interviewees' feedback, at this stage, the services provided by the library should include data management, research tools, data analysis and other services. Peking University Library provides a rich variety of research tools and services for the researchers, such as data analysis software, data management services, digital services, multimedia technology services. In addition, R\&D results between each group of data are confidential, so libraries also provide a number of standard international data, public patent information data, even market dynamics information to the researchers. Four major themes emerged for this question. 


\section{Research data management}

For researchers in the science field, Research Data Management is very important. Libraries provide research data management services which include collecting research data generated in the process, saving research data, building institutional repositories, providing text or data analysis tools, and providing files, data and other research data management services. Libraries not only standardize research management processes, also build research management platform.

Three of the 30 interviewees commented that they did not know that the library could do "Data Management," or that they did not know what the service meant. They suggested libraries should focus on getting services in front of researchers and be prepared with a simple explanation of what data management includes. One interviewee commented, "I think that what a librarian normally does is for books, but now I realize that they can do something for data. And this is a need for me and my team." Thus it can be seen there is still a little confusion about the role of libraries in data management, and researchers do not necessarily see why they should talk to a librarian about data. Sharing specific examples and success stories can help to counter this attitude.

More pleasing, most researchers (27/30) did know about the role of the Library in data management, an interviewee pointed out that "I know the institutional repository constructed by the library, and in the future I want my articles to be submitted to the institutional repository, so I can share my opinion with more researchers and get more access to others' achievements or scientific materials." Peking University Library constructed their research data open platform to support research data management, storage and publishing, promote reusing and standardizing the data. (Dataverse Project, 2016)

\section{Data analysis consulting services}

Data Analysis Consulting Services consists of two parts. On the one hand, the libraries provide statistical analysis tools and platform, and carry out training on the use of this software. On the other hand, we help users perform data mining, data analysis and data integration in order to meet the needs of the user's decision-making and innovation.

Many interviewees (24/30) indicated interest in Data Analysis Consulting Services. Some of them noted that to them this service meant the libraries would provide statistical analysis tools and platforms, and carry out training in the use of software, and others insisted librarians should also help researchers perform data mining, data analysis and data integration in order to meet the needs of the user decision-making and innovation.

One interviewee shared the experience, "our school wanted to investigate the distribution of the discipline of Topology accurately and rapidly, so the librarian was asked to analyze the research literatures on this discipline including authors, institutions, publication names, and countries from the WOS database. The librarian retrieved the results of a detailed analysis, revealed the current international research status, main academic institutions, discussed the main research directions of the subject area by the means of WOS and INCITES. These works are wonderful, and we really appreciate the library." 


\section{Database and research tools application consultation}

Research tools generally refer to computer software and network technology related to research including document management tools, information search tools, research aids, online learning platforms, and Open Access technology. Chinese college and university libraries mostly provide SPSS statistical analysis, AutoCAD-aided design, ZineMaker, electronic books and Document management tools such as NoteExpress, RefWorks, Endnote and related training. One interviewee commented, "I'm a new teacher and I want my students be proficient with the document management tools."

\section{Results and Output Phase}

As research progresses, results are produced in succession. The interviewees were asked a question about need for services provided by the libraries at this stage.

\section{Q3: What do libraries need to do at the Results and output stage of scientific research?}

From the survey, we found that at this stage, researchers most need academic publishing services, patent information services, and writing help. Therefore, the libraries provide services such as academic publishing, Open Access, copyright consulting, Institutional Repository and other services for the purpose of publication and long-term preservation of scientific research results. Three major themes emerged for this question.

\section{Patent information service}

Several researchers $(6 / 30)$ mentioned an interest in patent services due to their need to apply for patents in the process of scientific research. Patent information services provided by libraries are based on reviewing the patent literature for technical information, economic information and legal information. A researcher described how he hoped this service would work: "Through scientific processing, collation and analysis, the library can get patent information about products with high technical and commercial value, and use this patent information to provide the appropriate services for us."

The following patent review (Figure 5) provides an example: 


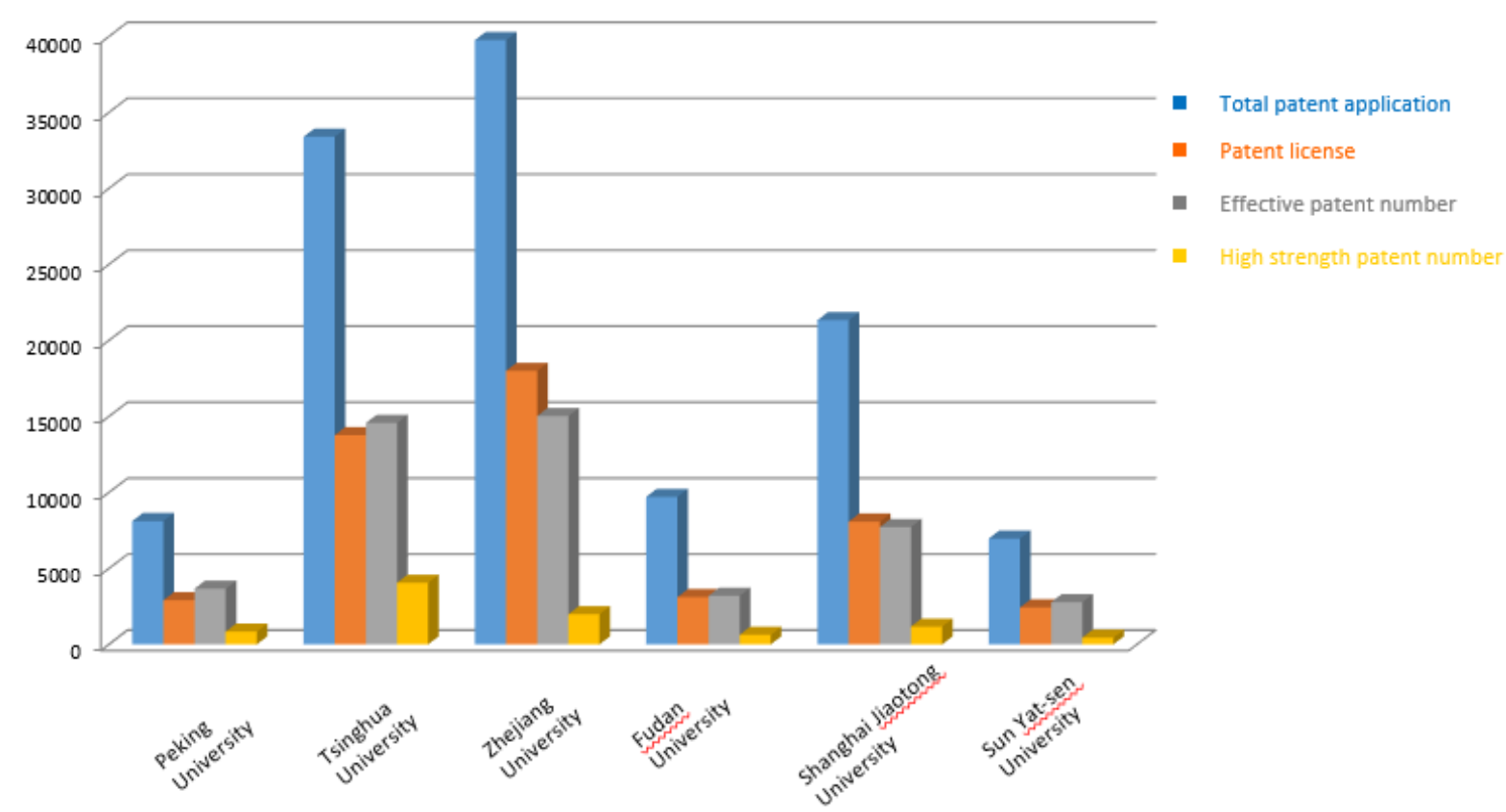

Figure 5. Comparison of each patent application, authorization, the number of valid patent and high strength of patent. Adapted from Analysis report on patent competitiveness of Peking University (page 24) by L.P. Wang, X.W. Liu, C.H. Zhang \& Y.Q. Liu (2016). Internal Peking University Library report: unpublished. Adapted with permission.

We can see that in terms of the amount of patent applications and licensing, Tsinghua University and Zhejiang University have a significant number of advantages over Peking University. (Wang, Liu, Zhang \& Liu, 2016)

\section{Academic achievements cited or evaluated report}

Citation retrieval is a service for Chinese researchers that analyzes how a paper was cited in databases such as WOS, SCOPUS, CSCD and CSSCI, and creates a search certificate report as a result for researchers. At present, these kinds of certificate reports are needed in many research approvals or offers to help validate the ability and level of researchers. Several interviewees (10/30) asked more about this service for the purpose of coming funding applications.

\section{Research data management}

This service was discussed at the second stage in detail, so at this stage, all interviewees (30/30) showed interest in this service.

\section{Writing help}

At this stage, subject librarians may be asked for writing help. Peking University library wants to not only to provide writing consultation, but also to be embedded into the researchers' projects in order to give submission suggestions and advice on how to meet academic standards. Several 
interviewees (11/30) indicated interest in this service. One interviewee commented: "At the stage of writing, students really need instruction in writing skills and copyright."

\section{Additional Observations}

The interviews were designed to collect needs for the library service model and gain insights on how to effectively deploy the model. In addition to being asked about the needs of each of these phases, interviewees also answered the following questions.

\section{Q4: Is there any possibility of collaborating with librarians?}

In order to increase the interviewees' awareness of librarian collaborations, the author introduced a project being conducted for the discipline office of Peking University, the library's Peking University Competitive analysis report (http://www.lib.pku.edu.cn/portal/en/fw/kyzc/jingzhengqingbao). Most interviewees showed some interest in this service. An interviewee mentioned that she hoped that librarians would be able to introduce library related resources and services in her class. This researcher was familiar with the library and she noted: "Good collaboration comes from good relationships between the librarian and the teachers, and a good librarian will do anything to achieve that."

Q5: Which problems and benefits have you experienced with use of the library, and do you have any suggestions for addressing the problems?

Several interviewees mentioned that libraries need to not only count the number of documents, analyze the structure of documents, and analyze the utilization of literature and reader satisfaction for the existing library collection, but also need to meet the needs of researchers by revealing weaknesses in the quality of their collections, amend and improve the collection, optimize the structure of the collection, and even just get information for the readers. An interviewee shared his experience: "Once I needed to find an article, the library did not have the journal on the shelf, so I tried to ask the librarian for help who immediately helped me look for it in the database, finally we found the e-journal. I was very grateful to the librarian for her work."

\section{Q6: Is there anything you would like to add that I haven't asked?}

There were a wide variety of responses to this catch-all question. Many interviewees reflected on the challenge of embedding library services in the different stages of scientific activities. "The library should build a team for this", "If possible, library should provide more public spaces." An interviewee spoke about this approach: "I deal with research data management issues all day that are arising more and more frequently in my everyday jobs, perhaps it's really an exciting opportunity for me and for librarians. I think it's fantastic that librarians have such willingness to embrace this new part of their job and create a better support service for researchers." 


\section{CONCLUSIONS}

Library programs help students and teachers become active and efficient users of information. Based on the interviews, we have found that researchers need research librarians to provide support across the three main research stages: project preparatory stage, research and development stage, results and output stage. The services offered by Peking University Library do a good job of providing this support, though clearly some services are more popular than others.

Library services are important in every stage of the research process. A variety of issues were raised when prompting interviewees on services they would like the library to offer, and the scientific activities significantly influenced library resources construction, library services, library facilities and even the future of the library. Luckily, more and more librarians focus on researchers'

various needs. Libraries can grasp the needs of researchers through the research process, clarify the type of service, find new service point, and provide innovative services.

Scientific research is a discovery process, the research libraries in the world should pay more attention to embedding all-round services for the researchers in all stages of scientific research on the basis of traditional services. It is not only the active response to the change of the external information environment, but also a change of the library service concept based on the scientific research life cycle. Libraries should actively embed library services in scientific research in order to support researchers to find, manage and make good use of scientific data resources, promote scientific development, and ultimately better establish a user-driven library.

\section{References}

Cornell University Library. (2011). Toward 2015: Cornell University Library Strategic Plan, 2011-2015. Retrieved July 11, 2017 from https://www.library.cornell.edu/about/inside/strategic-plan

Dataverse Project. (2016). Q \& A with Peking University Dataverse. Retrieved July 4, 2017 from https://dataverse.org/blog/q-peking-university-dataverse

Fourie, I. and Bakker, S. (2013). Value of a manageable research life cycle for LIS: A cancer library exploring the needs of clinicians and researchers as example. The Electronic Library, 31(5), 648-663.

Jisc. (2013). How Jisc is helping researchers. Retrieved July 11, 2017 from http://www.jisc.ac.uk/whatwedo/campaigns/res3/jischelp.aspx\#simulate

McKenzie, E. (2014), Academic libraries and outreach to the sciences: taking a closer look at research groups. Science \& Technology Libraries, 33(2), 165-175.

Pang, B. (2012). Study on the library subject service based on e-science and the life cycle theory of research. Library Work in Colleges and Universities, 32(150), 81-83. [in Chinese] 
Peking University Library. (n. d. a). Research management and decision-making support. Retrieved July 11, 2017 from http://www.lib.pku.edu.cn/portal/en/fw/kyzc/guanliyujuecezhichi

Peking University Library. (n. d. b). Research Support. Retrieved July 12, 2017 from http://www.lib.pku.edu.cn/portal/en/fw/kyzc/ketizixun

Rodwell, J. and Fairbairn, L. (2008). Dangerous liaisons? Defining the faculty liaison librarian service model, its effectiveness and sustainability. Library Management, 29(1-2), 116124.

Song, H., Guo, J., and Pan. W. (2012), Practical exploration on embedded subject service oriented research teams. Library and Information Service, 56(1), 27-30. [in Chinese]

Vaughan, K., Hayes, B. E., Lerner, R. C., McElfresh, K. R., Pavlech, L., Romito, D., Reeves, L., and Morris, E. N. (2013). Development of the research lifecycle model for library services. Journal of the Medical Library Association: JMLA, 101(4), 310-314. http://doi.org/10.3163/1536-5050.101.4.01318

Wang, L.P., Liu, X.W., Zhang, C.H. \& Liu, Y.Q. (2016). Analysis report on patent competitiveness of Peking University. Internal Peking University Library report: unpublished.

Wang, X. (2014), An empirical study on the discipline service model embedded in scientific research process. Information Studies: Theory \& Application, 37(12), 81-85. [in Chinese]

Weiming Academic Express. (July 5, 2016). Peking University increases 1 top 1\% and 1 top $0.1 \%$ disciplines in May 2016. Retrieved from http://weibo.com/u/5963822635?profile_ftype=1\&is_all=1\#_rnd1499825188373. [in Chinese]

\section{Appendices:}

\section{Interview Questions}

Q1: What do you need libraries to do during the project preparatory stage of scientific research? Please see this list of library services. (Shows list.) What you are interested in? Could you also suggest other services you need?

Q2: What do you need libraries to do during the Development and Research Phase of scientific research? Please see this list of library services. (Shows list.) What you are interested in? Could you also suggest other services you need?

Q3: What do you need libraries to do during the Results and output stage of scientific research? Please see this list of library services. (Shows list.) What you are interested in? Could you also suggest other services you need?

Q4: Why do you use information to complete the daily tasks? 
Q5: How do you usually use the library?

Q6: Is there any possibility of collaborating with librarians?

Q7: Which problems and benefits experienced with use of the library, and suggestions for addressing the problems?

Q8: Is there anything you would like to add that I haven't asked?

\section{List of Library Services}

\begin{tabular}{|l|l|}
\hline No. & Library Services \\
\hline 1 & Book Borrows, Recalls, Renewal \\
\hline 2 & Interlibrary Loan \\
\hline 3 & Scanning, Digitizing, Multimedia Content Editing \\
\hline 4 & Providing Research Information \\
\hline 5 & Discipline Resources Construction \\
\hline 6 & Patent Information Service \\
\hline 7 & Discipline Development Supporting \\
\hline 8 & Data Analysis Consulting Services \\
\hline 9 & Research Data Management \\
\hline 10 & Database and Research Tools Application consultation \\
\hline 11 & Academic Achievements Cited or Evaluated Report \\
\hline 12 & Training in Literature Searches \\
\hline 13 & Build Service Platform \\
\hline 14 & Self-Service (Print, Photocopy, Scan) \\
\hline 15 & Writing help \\
\hline
\end{tabular}

\section{About the author}

Shu Liu is an associate professor in the Peking University Library. She joined the library in 2005. Her research interests include knowledge management, LIS education and research supporting services. She has published more than ten journal articles and presented to a number of conferences. 